\section{Tradução, adaptação transcultural e validação de conteúdo da versão em português do Coping Behaviours Inventory (CBI) para a população brasileira}

\author{
Translation, cross-cultural adaptation, and content \\ validation of the Portuguese version of the \\ Coping Behaviours Inventory (CBI) for the \\ Brazilian population
}

\author{
Traducción, adaptación cultural y validación del \\ contenido de la versión en portugués del Coping \\ Behaviours Inventory (CBI) para la población \\ brasileña
}

\begin{abstract}
Coping skills correlate directly with the success of alcohol abstinence. Brazil previously lacked an instrument to identify alcohol users' specific coping skills. The current study therefore aimed to perform the translation, cross-cultural adaptation, and content validation of the Coping Behaviours Inventory (CBI). Procedures included translation and back-translation, cross-cultural adaptation, content evaluation, and a pilot study. The final Portuguese version was administered by telephone to 40 alcohol users seeking help through a telephone hotline called VIVAVOZ. The retranslated version was close to the original. As for content validation, most of the items proved satisfactory and acceptable. The theoretical dimension showed a mean kappa index of 0.666 between evaluators, which was considered a substantial level of agreement. The results were satisfactory and acceptable, demonstrating that the inventory is appropriate for investigating coping skills in Brazilian alcohol users.
\end{abstract}

Alcoholism; Questionnaires; Translating
Hilda Maria Rodrigues Moleda Constant 1 Luciana Rizzieri Figueiró 1

Luciana Signor 1

Nadia Krubskaya Bisch 1

Helena Maria Tanhauser Barros 1

Maristela Ferigolo 1

\section{Resumo}

Estratégias de coping relacionam-se diretamente com o sucesso de abstinência do uso de álcool. No Brasil não há instrumentos que identifiquem estratégias específicas para usuários de álcool. O objetivo deste estudo foi realizar a tradução, adaptação transcultural e validação de conteúdo do Coping Behaviours Inventory (CBI). Os procedimentos seguiram de tradução e retradução, adaptação transcultural, avaliação de conteúdo e estudo piloto. A versão final em português foi aplicada por telefone a 40 usuários de álcool que buscaram auxílio em um serviço de teleatendimento, o VIVAVOZ. A versão retraduzida aproximou-se da original. Quanto à validação de conteúdo, a maioria dos itens é satisfatória e aceitável. Além disso, a concordância entre os juízes, referente à dimensão teórica, apresentou índice kappa médio igual a 0,666, sendo o nível de concordância considerado substancial. Os resultados são satisfatórios e aceitáveis, o que demonstra que a escala está adequada para investigar as estratégias de coping para usuários de álcool.

Alcoolismo; Questionários; Tradução 


\section{Introdução}

Para problemas gerados pelo consumo de álcool são necessárias ferramentas que auxiliem na cessação do uso, adesão ao tratamento e manutenção da abstinência 1,2. Essas ferramentas possibilitam identificar estratégias para melhorar as habilidades do indivíduo, sua eficácia e como aplicá-las em situações de risco 3,4.

O Coping Behaviours Inventory (CBI) é um instrumento que demonstra situações vivenciadas por adultos usuários de álcool. Contém 36 itens nos quais o respondente indica com que frequência cada estratégia de coping é utilizada. As respostas resultam em fatores relacionados a pensamento positivo; pensamento negativo; evitação/distração e suporte social. O instrumento avalia comportamentos e pensamentos usados por alcoolistas para prevenir, evitar ou controlar a retomada do beber ${ }^{3}$. Esse inventário foi originalmente proposto para ser autoaplicado pela população britânica usuária de álcool, e houve uma adaptação do mesmo na Espanha onde demonstrou alta confiabilidade e validade de construto nesta versão ${ }^{5}$.

Objetivou-se realizar a tradução, adaptação transcultural e validação de conteúdo do CBI para aplicação em usuários de álcool brasileiros que procuraram um serviço de telessaúde.

\section{Método}

O processo de tradução, adaptação transcultural e validação de conteúdo do CBI seguiu os procedimentos indicados por Pasquali 6 (Figura 1).

\section{Etapa 1 - tradução}

Por ser um instrumento com características multidimensionais, optou-se pela técnica de tradução reversa/retradução, (1) realizou-se a tradução do instrumento original (versão inglês) para o português por brasileiro com domínio do idioma inglês; e (2) a versão traduzida (português) foi retraduzida para o inglês original por um nativo de língua inglesa com fluência na língua portuguesa. Esse, não participou do primeiro passo e também não conhecia o instrumento original.

\section{Etapa 2 - consolidação da tradução}

Por meio do método de comitê, realizou-se avaliação item a item das retraduções para verificar se a proposta da versão final se aproximava da versão original. O objetivo foi unificar as versões de tradução e obter consenso referente ao conteúdo explorado. O comitê foi composto por três
Figura 1

Fluxograma das etapas de adaptação transcultural e validação de conteúdo do Coping Behaviours Inventory (CBI).

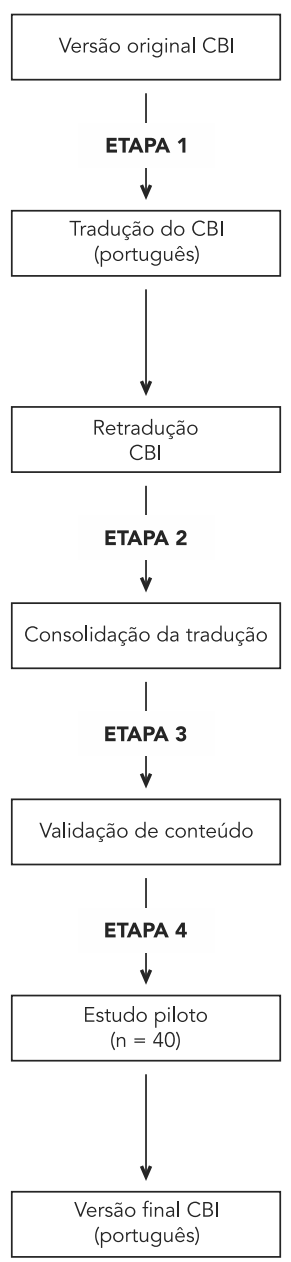

profissionais: dois pesquisadores brasileiros com domínio da língua inglesa e atuação na área da dependência química, sendo um destes autor da versão traduzida; e uma professora de língua inglesa com fluência na língua portuguesa.

\section{Etapa 3 - validação de conteúdo}

Contou-se com cinco juízes avaliadores, que verificaram se o teste em questão media o que se propunha. A avaliação dos itens por cada juiz foi realizada mediante uma escala do tipo Likert ( 1 = pouquíssima, 2 = pouca, 3 = média, 4 = muita 
e 5 = muitíssima) para os critérios: (1) clareza de linguagem - considera a linguagem utilizada nos itens, visando às características da população respondente; (2) pertinência prática - considera se cada item foi elaborado para avaliar o conceito de interesse dos entrevistados e, ainda, se cada item possui importância para o instrumento; e (3) relevância teórica - considera o grau de associação entre o item e a teoria, ou seja, se o item está relacionado com o constructo. Utilizou-se o coeficiente de validade de conteúdo (CVC) ${ }^{6}$ para avaliar a concordância entre os juízes.

Avaliou-se a dimensão teórica, que investiga se cada item demonstra pertencer ao seu referente fator. Nesse critério foi avaliada a média do coeficiente kappa, o qual possibilitou verificar a concordância entre a avaliação desses juízes. Os critérios para a interpretação do coeficiente kappa utilizados foram $<0=$ discordância; $0-0,20=$ quase nenhum; $0,20-0,40=$ pequeno; $0,40-0,60=$ moderado; $0,60-0,80=$ substancial; $0,80-1,00=$ quase perfeito 7 .

Além disso, disponibilizou-se espaço para observações que foram descritas no decorrer da avaliação como possíveis formas de melhorar cada questão.

\section{Etapa 4 - estudo piloto}

A versão final foi aplicada individualmente e por telefone a uma amostra de conveniência com quarenta usuários de álcool em acompanhamento telefônico no Serviço Nacional de Orientações e Informações sobre o Uso de Drogas, no período de julho a setembro de 2011. A entrevista foi realizada por quatro assistentes, treinados, com ligações proativas (realizadas pelo serviço) a esses usuários. Os entrevistadores tornaramse proficientes para realizar a pesquisa por meio de treinamentos para o teleatendimento e para o protocolo desta pesquisa ${ }^{8}$. O piloto objetivou a adequação gramatical e funcional do instrumento para ser aplicada por telefone, pela avaliação do grau de compreensão de cada questão e do instrumento em sua íntegra. Ao término da aplicação foi solicitado ao entrevistado que referisse suas sugestões, caso percebesse alguma dificuldade para a compreensão dos itens que compõem o instrumento. Caso houvesse sugestões, estas eram devidamente anotadas pelo entrevistador. A repetição de itens pelos entrevistados demonstrou confiabilidade das respostas. Averiguou-se o tempo de aplicação do instrumento. Esta etapa foi importante para assegurar que a versão adaptada retém sua equivalência no momento da aplicação.
O estudo foi aprovado pelo Comitê de Ética em Pesquisa da Universidade Federal de Ciências da Saúde de Porto Alegre (UFCSPA) sob parecer $121510 / 2010$.

\section{Resultados}

Na etapa 1, retradução, observou-se que os itens do instrumento estrangeiro se mostraram semelhantes aos do retraduzido, demonstrando que esta versão se aproximou da original.

$\mathrm{Na}$ etapa 2, analisaram-se pontos convergentes e divergentes das traduções. Realizou-se alterações para salientar que as afirmativas se referiam ao uso de álcool (itens 6 e 18), bem como esclarecer expressões populares ("um mar de rosas", “...afogá-los...”). O comitê de avaliadores realizou alterações nos itens 5, 6, 11, 15, 18,19, 24 e 31 da versão traduzida (Tabela 1).

$\mathrm{Na}$ etapa 3, foi feita a análise dos escores obtidos dos avaliadores sobre o instrumento segundo princípios matemáticos 7 . A maioria dos itens obteve $\mathrm{CVC}>0,80$, que corresponde à validade satisfatória e aceitável. Nas questões em que o coeficiente foi inferior a 0,80 (1, 2, 6 e 18), optou-se por uma reformulação baseada nas considerações sugeridas pelos juízes avaliadores (Tabela 1). Na avaliação da dimensão teórica, calculada pelo coeficiente kappa, observou-se que o valor médio do coeficiente caracterizou-se como nível de concordância "substancial" $\left(K_{\text {médio }}=\right.$ 0,660 ) conforme Landis \& Koch 9 . A Tabela 2 mostra os escores do CVC para cada item com relação aos critérios avaliados.

Os dados referentes à validação de conteúdo apontam que a escala está adequada para aplicação individual por telefone em usuários de álcool brasileiros.

Na etapa 4 - estudo piloto - a amostra incluiu 25 usuários do sexo masculino (62,5\%) e 15 do feminino (35,5\%), 60\% com idades entre 18 e 35 anos, $71,4 \%$ com renda até $\mathrm{R} \$ 1.500,00$ e $81 \%$ estavam empregados. Foram excluídos os participantes que estavam sob efeito de substância psicoativa e aqueles que se negaram a participar do estudo, após a leitura do Termo de Consentimento Livre e Esclarecido. A aplicação do instrumento demandou aproximadamente vinte minutos.

\section{Discussão}

Estratégias de coping são determinantes importantes na abstinência do uso de álcool, variando conforme o ambiente ou a situação de risco à qual o indivíduo é exposto ${ }^{3}$. A identificação de estratégias específicas que auxiliam a população 
Tabela 1

Coping Behaviours Inventory (CBI): versão original, tradução para o português, retradução e versão final em português.

\begin{tabular}{|c|c|c|c|}
\hline Versão original & Tradução & Retradução & Versão final em português \\
\hline $\begin{array}{l}\text { 1. Thinking about how } \\
\text { much better off I am without } \\
\text { drinking.* }\end{array}$ & $\begin{array}{l}\text { 1. Pensando sobre quanto melhor } \\
\text { eu sou sem beber. * }\end{array}$ & $\begin{array}{l}\text { 1. Thinking hinking about how much } \\
\text { better I am when I don't drink. * }\end{array}$ & $\begin{array}{l}\text { 1. Pensar sobre o quanto melhor eu } \\
\text { sou sem beber *. }\end{array}$ \\
\hline 2. Telephoning a friend. * & 2. Telefonando para um amigo. * & 2. Telephoning a friend. * & 2. Telefonar para um amigo. * \\
\hline $\begin{array}{l}\text { 3. Keeping in the company of } \\
\text { non drinkers. }\end{array}$ & $\begin{array}{l}\text { 3. Mantendo-se em companhia dos } \\
\text { não bebedores. }\end{array}$ & $\begin{array}{l}\text { 3. Keeping company with } \\
\text { non drinkers. }\end{array}$ & $\begin{array}{l}\text { 3. Manter-me em companhia de } \\
\text { pessoas que não bebem. }\end{array}$ \\
\hline 4. Thinking positively & 4. Pensar positivamente. & 4. Thinking positively. & 4. Pensar positivamente. \\
\hline $\begin{array}{l}\text { 5. Thinking of the mess I've got } \\
\text { myself into through drinking. ** }\end{array}$ & $\begin{array}{l}\text { 5. Pensando na confusão em que eu } \\
\text { me meti bebendo. }{ }^{\star \star}\end{array}$ & $\begin{array}{l}\text { 5. Thinking of the mess that I have } \\
\text { in me through drinking. ** }\end{array}$ & $\begin{array}{l}\text { 5. Pensar nos problemas em que eu } \\
\text { me meti bebendo. ** }\end{array}$ \\
\hline $\begin{array}{l}\text { 6. Stopping to examine my } \\
\text { motives and eliminating the } \\
\text { false ones. * }\end{array}$ & $\begin{array}{l}\text { 6. Parando para examinar meus } \\
\text { motivos e eliminando as mentiras. * }\end{array}$ & $\begin{array}{l}\text { 6. Stopping to examine my motives } \\
\text { and eliminating lies. * }\end{array}$ & $\begin{array}{l}\text { 6. Examinar meus motivos para } \\
\text { cessar o uso de álcool e não mentir } \\
\text { sobre meu consumo. * }\end{array}$ \\
\hline $\begin{array}{l}\text { 7. Thinking of the promises I've } \\
\text { made to others. }\end{array}$ & $\begin{array}{l}\text { 7. Pensando nas promessas que fiz } \\
\text { para outros. }\end{array}$ & $\begin{array}{l}\text { 7. Thinking of the promises I have } \\
\text { made to others. }\end{array}$ & $\begin{array}{l}\text { 7. Pensar nas promessas que fiz aos } \\
\text { outros para parar de beber. }\end{array}$ \\
\hline 8. Staying indoors - hiding & $\begin{array}{l}\text { 8. Ficar dentro de casa - se } \\
\text { escondendo. }\end{array}$ & 8. Staying at home hiding. & $\begin{array}{l}\text { 8. Ficar dentro de casa me } \\
\text { escondendo. }\end{array}$ \\
\hline $\begin{array}{l}\text { 9. Pausing and really thinking } \\
\text { the whole alcoholic cycle } \\
\text { through. }\end{array}$ & $\begin{array}{l}\text { 9. Parar e realmente pensar todo o } \\
\text { ciclo do uso do álcool. }\end{array}$ & $\begin{array}{l}\text { 9. Stop and really thinking about the } \\
\text { whole cycle of the use of alcoholic. }\end{array}$ & $\begin{array}{l}\text { 9. Parar e realmente pensar todo o } \\
\text { ciclo do uso do álcool. }\end{array}$ \\
\hline $\begin{array}{l}\text { 10. Leaving my money at } \\
\text { home. }\end{array}$ & $\begin{array}{l}\text { 10. Deixando meu dinheiro } \\
\text { em casa. }\end{array}$ & 10. Leaving my money at home. & 10. Deixar meu dinheiro em casa. \\
\hline $\begin{array}{l}\text { 11. Recognizing that life is no } \\
\text { bed of roses but drink is not } \\
\text { the answer. ** }\end{array}$ & $\begin{array}{l}\text { 11. Reconhecendo que a vida não é } \\
\text { um mar de rosas, mas beber não } \\
\text { é a resposta. ** }\end{array}$ & $\begin{array}{l}\text { 11. Recognizing that life is not a bed } \\
\text { of roses but drinking is not } \\
\text { the answer. }{ }^{*}\end{array}$ & $\begin{array}{l}\text { 11. Reconhecer que a vida não é } \\
\text { feita somente de coisas boas, mas } \\
\text { beber não é a resposta. }{ }^{\star \star}\end{array}$ \\
\hline 12. Going to an A.A. meeting. & 12. Ir a uma reunião do A.A. & 12. Going to an A.A. meeting. & $\begin{array}{c}\text { 12. Ir a uma reunião de grupo } \\
\text { de autoajuda como Alcoólicos } \\
\text { Anônimos. }\end{array}$ \\
\hline $\begin{array}{l}\text { 13. Knowing that by not } \\
\text { drinking I can show my face } \\
\text { again without fear of what } \\
\text { others will think. }\end{array}$ & $\begin{array}{l}\text { 13. Sabendo que por não beber } \\
\text { eu posso mostrar o meu rosto sem } \\
\text { medo do que os outros vão pensar. }\end{array}$ & $\begin{array}{l}\text { 13. Knowing that by not drinking I } \\
\text { can show my face without fear of } \\
\text { what others will think. }\end{array}$ & $\begin{array}{l}\text { 13. Saber que por não beber eu } \\
\text { posso aparecer para as pessoas e } \\
\text { mostrar o meu rosto sem medo do } \\
\text { que os outros vão pensar. }\end{array}$ \\
\hline $\begin{array}{l}\text { 14. Cheering myself up by } \\
\text { buying myself something } \\
\text { special instead. }\end{array}$ & $\begin{array}{l}\text { 14. Animando-me e comprando } \\
\text { algo especial em vez da bebida. }\end{array}$ & $\begin{array}{l}\text { 14. Supporting myself I can buying } \\
\text { myself something special instead of } \\
\text { alcohol. }\end{array}$ & $\begin{array}{l}\text { 14. Ficar animado ou comprar algo } \\
\text { especial em vez da bebida. }\end{array}$ \\
\hline $\begin{array}{l}\text { 15. Facing up to my bad } \\
\text { feelings instead of trying to } \\
\text { drown them. }{ }^{\star \star}\end{array}$ & $\begin{array}{l}\text { 15. Enfrentando os meus } \\
\text { sentimentos ruins em vez de tentar } \\
\text { afogá-los. ** }\end{array}$ & $\begin{array}{l}\text { 15. Facing my bad feelings instead } \\
\text { of trying to drown them. ** }\end{array}$ & $\begin{array}{l}\text { 15. Enfrentar os meus sentimentos } \\
\text { ruins ao invés de tentar "afogá-los"/ } \\
\text { esquecê-los. ** }\end{array}$ \\
\hline 16. Working harder. & 16. Trabalhando duro. & 16. Working harder. & 16. Trabalhar duro. \\
\hline $\begin{array}{l}\text { 17. Realizing it's just not worth } \\
\text { it. }\end{array}$ & $\begin{array}{l}\text { 17. Percebendo que simplesmente } \\
\text { não vale à pena. }\end{array}$ & $\begin{array}{l}\text { 17. Realizing that it simply isn't } \\
\text { worth it. }\end{array}$ & $\begin{array}{l}\text { 17. Perceber que simplesmente não } \\
\text { vale a pena beber. }\end{array}$ \\
\hline $\begin{array}{l}\text { 18. Waiting it out until } \\
\text { everything is shut. * }\end{array}$ & $\begin{array}{l}\text { 18. Esperando até que tudo } \\
\text { esteja fechado. * }\end{array}$ & $\begin{array}{l}\text { 18. Waiting until everything is } \\
\text { closed. * }\end{array}$ & $\begin{array}{c}\text { 18. Esperar até que todos os locais } \\
\text { onde vendem bebidas estejam } \\
\text { fechados. * }\end{array}$ \\
\hline $\begin{array}{l}\text { 19. Remembering how l've let } \\
\text { my friends and family down in } \\
\text { the past. ** }\end{array}$ & $\begin{array}{l}\text { 19. Lembrando como eu deixei } \\
\text { minha família e amigos para baixo } \\
\text { no passado. }{ }^{* \star}\end{array}$ & $\begin{array}{l}\text { 19. Remembering how l've let my } \\
\text { friends and family down in } \\
\text { the past. }{ }^{*}\end{array}$ & $\begin{array}{l}\text { 19. Lembrar como eu deixei minha } \\
\text { família e amigos "para baixo", mal, } \\
\text { triste, em situações difíceis } \\
\text { no passado. }{ }^{\star \star}\end{array}$ \\
\hline $\begin{array}{l}\text { 20. Keeping away from people } \\
\text { who drink. }\end{array}$ & $\begin{array}{l}\text { 20. Mantendo-me longe das } \\
\text { pessoas que bebem. }\end{array}$ & $\begin{array}{l}\text { 20. Keeping myself far away from } \\
\text { people who drink. }\end{array}$ & $\begin{array}{l}\text { 20. Manter-me longe das pessoas } \\
\text { que bebem. }\end{array}$ \\
\hline
\end{tabular}

(continua) 
Tabela 1 (continuação)

\begin{tabular}{|c|c|c|c|}
\hline Versão original & Tradução & Retradução & Versão final em português \\
\hline 21. Going for a walk. & 21. Saindo para uma caminhada. & 21. Going for a walk. & 21. Fazer uma caminhada. \\
\hline $\begin{array}{l}\text { 22. Looking on the bright side } \\
\text { and trying to stop making }\end{array}$ & $\begin{array}{l}\text { 22. Olhando o lado bom e tentando } \\
\text { parar de inventar desculpas para }\end{array}$ & $\begin{array}{l}\text { 22. Looking on the bright side } \\
\text { and trying to stop making excuses }\end{array}$ & $\begin{array}{l}\text { 22. Olhar o lado bom de parar com } \\
\text { o uso de álcool e tentar parar de }\end{array}$ \\
\hline excuses for myself. & mim mesmo. & for myself. & $\begin{array}{l}\text { inventar desculpas para } \\
\text { mim mesmo. }\end{array}$ \\
\hline $\begin{array}{l}\text { 23. Realizing it's affecting my } \\
\text { health }\end{array}$ & $\begin{array}{l}\text { 23. Percebendo que está afetando } \\
\text { minha saúde. }\end{array}$ & $\begin{array}{l}\text { 23. Realizing that drinking was } \\
\text { affecting my health. }\end{array}$ & $\begin{array}{l}\text { 23. Perceber que o uso do álcool } \\
\text { está afetando minha saúde. }\end{array}$ \\
\hline $\begin{array}{l}\text { 24. Start doing something in } \\
\text { the house. }{ }^{\star \star}\end{array}$ & $\begin{array}{l}\text { 24. Começando a fazer algo em } \\
\text { casa. }{ }^{\star \star}\end{array}$ & $\begin{array}{l}\text { 24. Start doing something } \\
\text { at home. ** }\end{array}$ & $\begin{array}{l}\text { 24. Começar a fazer alguma } \\
\text { atividade em casa para me distrair e } \\
\text { evitar o uso do álcool. ** }\end{array}$ \\
\hline $\begin{array}{l}\text { 25. Considering the effect it will } \\
\text { have on my family. }\end{array}$ & $\begin{array}{l}\text { 25. Considerando os efeitos que } \\
\text { terá na minha família. }\end{array}$ & $\begin{array}{l}\text { 25. Considering the effect that } \\
\text { drinking could have on my family. }\end{array}$ & $\begin{array}{l}\text { 25. Considerar os efeitos que o uso } \\
\text { do álcool terá na minha família. }\end{array}$ \\
\hline $\begin{array}{l}\text { 26. Reminding myself of the } \\
\text { good life I can have } \\
\text { without drink. }\end{array}$ & $\begin{array}{l}\text { 26. Lembrando-me da boa vida que } \\
\text { eu poderia ter sem beber. }\end{array}$ & $\begin{array}{l}\text { 26. Reminding of the good life that I } \\
\text { could have without drinking. }\end{array}$ & $\begin{array}{l}\text { 26. Lembrar da boa vida que eu } \\
\text { poderia ter sem beber. }\end{array}$ \\
\hline $\begin{array}{l}\text { 27. Getting in touch with old } \\
\text { drinking friends who are } \\
\text { better now. }\end{array}$ & $\begin{array}{l}\text { 27. Fazendo contato com antigos } \\
\text { amigos que bebiam e estão } \\
\text { recuperados agora. }\end{array}$ & $\begin{array}{l}\text { 27. Entering in contact with old } \\
\text { friends that drank and are } \\
\text { better now. }\end{array}$ & $\begin{array}{l}\text { 27. Fazer contato com amigos } \\
\text { antigos que bebiam e estão } \\
\text { recuperados agora. }\end{array}$ \\
\hline $\begin{array}{l}\text { 28. Making up my mind that } \\
\text { I'm going to stop playing } \\
\text { games with myself. }\end{array}$ & $\begin{array}{l}\text { 28. Decidindo que eu vou parar de } \\
\text { brincar comigo mesmo. }\end{array}$ & $\begin{array}{l}\text { 28. Put it in my mind that I will stop } \\
\text { playing with myself. }\end{array}$ & $\begin{array}{l}\text { 28. Decidir que eu vou parar de } \\
\text { "brincar" comigo mesmo. }\end{array}$ \\
\hline $\begin{array}{l}\text { 29. Eating a good meal. } \\
\text { 30. Avoiding places where } \\
\text { I drank. }\end{array}$ & $\begin{array}{l}\text { 29. Comendo uma boa refeição. } \\
\text { 30. Evitando lugares onde eu bebia. }\end{array}$ & $\begin{array}{l}\text { 29. Eating a good meal. } \\
\text { 30. Avoiding places where I drank. }\end{array}$ & $\begin{array}{l}\text { 29. Comer uma boa refeição. } \\
\text { 30. Evitar lugares onde eu bebia. }\end{array}$ \\
\hline $\begin{array}{l}\text { 31. Thinking about all the people } \\
\text { who have helped me. }{ }^{\star \star}\end{array}$ & $\begin{array}{l}\text { 31. Pensando em todas as pessoas } \\
\text { que me ajudaram. }{ }^{\star \star}\end{array}$ & $\begin{array}{l}\text { 31. Thinking of all the people that } \\
\text { have helped me. }{ }^{*}\end{array}$ & $\begin{array}{l}\text { 31. Pensar que posso decepcionar } \\
\text { as pessoas que me ajudaram. }{ }^{\star}\end{array}$ \\
\hline $\begin{array}{l}\text { 32. Saying I am well and wish } \\
\text { to stay so. }\end{array}$ & $\begin{array}{l}\text { 32. Dizendo que estou bem e } \\
\text { desejo continuar assim. }\end{array}$ & $\begin{array}{l}\text { 32. Saying that I am good and } \\
\text { would like to stay that way }\end{array}$ & $\begin{array}{l}\text { 32. Dizer que estou bem e desejo } \\
\text { continuar assim. }\end{array}$ \\
\hline 33. Going to sleep. & 33. Indo dormir. & 33. Going to sleep. & 33. Ir dormir. \\
\hline $\begin{array}{l}\text { 34. Remembering how it has } \\
\text { affected my family. }\end{array}$ & $\begin{array}{l}\text { 34. Lembrando como isso afetou a } \\
\text { minha família. }\end{array}$ & $\begin{array}{l}\text { 34. Remembering about how this } \\
\text { affected my family. }\end{array}$ & $\begin{array}{l}\text { 34. Lembrar de como isso afetou a } \\
\text { minha família. }\end{array}$ \\
\hline $\begin{array}{l}\text { 35. Forcing myself to go to } \\
\text { work. }\end{array}$ & 35. Forçando-me a ir ao trabalho. & 35. Forcing myself to go to work. & 35. Forçar-me a ir ao trabalho. \\
\hline $\begin{array}{l}\text { 36. Trying to face life instead of } \\
\text { avoiding it }\end{array}$ & $\begin{array}{l}\text { 36. Tentando enfrentar em vez de } \\
\text { evitar a vida. }\end{array}$ & $\begin{array}{l}\text { 36. Trying to face life rather than } \\
\text { avoiding it. }\end{array}$ & $\begin{array}{l}\text { 36. Tentar enfrentar a vida ao invés } \\
\text { de evitá-la. }\end{array}$ \\
\hline
\end{tabular}

* Questões reformuladas com base nas considerações sugeridas pelos juízes avaliadores;

** Questões reformuladas com base nas alterações propostas pelo comitê de avaliadores (etapa 2).

de usuários de álcool pode facilitar o tratamento destes indivíduos e colaborar para um melhor planejamento do processo de parada do uso, assim como prevenir a recaída 1,10 .

Com a adaptação transcultural do CBI, foi possível adaptar à realidade da população brasileira uma escala validada e construída em inglês e já adaptada para o espanhol, que aborda questões específicas de estratégias de coping para prevenção de recaída do uso do álcool 3,5. A versão brasileira do CBI manteve o nome original em inglês acrescido de "versão brasileira", e demonstrou ser de fácil aplicação por telefone, em um curto espaço de tempo. O fato de o estudo piloto ter sido aplicado na população em que se pretendia utilizar o instrumento é um fator positivo na sua adaptação.

As etapas de tradução e retradução da versão original do CBI foram criteriosas, atingindo bons resultados da versão em português. Houve atenção especial para não usar expressões com influências regionais ou gírias utilizadas por dependentes químicos, pois, comumente, estas são modificadas ao longo do tempo. O fato de os juízes formarem um grupo multidisciplinar e com experiência na abordagem a dependentes 
Tabela 2

Resultados da avaliação dos juízes $(\mathrm{n}=5)$ na etapa de validação do conteúdo do Coping Behaviours Inventory (CBI).

\begin{tabular}{|c|c|c|c|c|c|c|c|}
\hline \multirow[t]{2}{*}{ Itens } & \multirow[t]{2}{*}{$\begin{array}{c}\text { Clareza de } \\
\text { linguagem (CVC) }\end{array}$} & \multirow[t]{2}{*}{$\begin{array}{l}\text { Pertinência } \\
\text { (CVC) }\end{array}$} & \multirow[t]{2}{*}{$\begin{array}{l}\text { Relevância teórica } \\
\text { (CVC) }\end{array}$} & \multicolumn{4}{|c|}{$\begin{array}{l}\text { Dimensão teórica } \\
\text { (kappa) }\end{array}$} \\
\hline & & & & PP & PN & $E / D$ & SS \\
\hline 1. Pensar sobre o quanto melhor eu sou sem beber. & 0,72 & 0,96 & 0,92 & 4 & 1 & & \\
\hline 2. Telefonar para um amigo. & 0,76 & 0,80 & 0,80 & & & & 5 \\
\hline 3. Manter-me em companhia de pessoas que não bebem. & 0,92 & 0,96 & 0,96 & & & & 5 \\
\hline 4. Pensar positivamente. & 0,88 & 0,84 & 0,88 & 4 & & & 1 \\
\hline 5. Pensar nos problemas em que eu me meti bebendo. & 0,84 & 0,88 & 0,84 & 1 & 4 & & \\
\hline $\begin{array}{l}\text { 6. Examinar meus motivos para cessar o uso de álcool e não } \\
\text { mentir sobre meu consumo. }\end{array}$ & 0,72 & 0,76 & 0,80 & 4 & 1 & & \\
\hline 7. Pensar nas promessas que fiz aos outros para parar de beber. & 0,88 & 0,84 & 0,80 & 3 & 2 & & \\
\hline 8. Ficar dentro de casa me escondendo. & 0,88 & 0,88 & 0,92 & & & 5 & \\
\hline 9. Parar e realmente pensar todo o ciclo do uso do álcool. & 1,00 & 1,00 & 1,00 & 3 & 2 & & \\
\hline 10. Deixar meu dinheiro em casa. & 0,92 & 0,96 & 0,92 & & & 5 & \\
\hline $\begin{array}{l}\text { 11. Reconhecer que a vida não é feita somente de coisas boas, } \\
\text { mas beber não é a resposta. }\end{array}$ & 1,00 & 0,96 & 0,92 & 4 & 1 & & \\
\hline $\begin{array}{l}\text { 12. Ir a uma reunião de grupo de autoajuda como Alcoólicos } \\
\text { Anônimos. }\end{array}$ & 1,00 & 1,00 & 1,00 & & & & 5 \\
\hline $\begin{array}{l}\text { 13. Saber que por não beber eu posso aparecer para as pessoas } \\
\text { e mostrar o meu rosto sem medo do que os outros vão pensar. }\end{array}$ & 1,00 & 0,96 & 0,96 & 5 & & & \\
\hline 14. Ficar animado ou comprar algo especial em vez da bebida. & 1,00 & 0,88 & 0,84 & 1 & & 4 & \\
\hline $\begin{array}{l}\text { 15. Enfrentar os meus sentimentos ruins ao invés de tentar } \\
\text { "afogá-los"/esquecê-los. }\end{array}$ & 0,96 & 1,00 & 0,92 & 4 & 1 & & \\
\hline 16. Trabalhar duro. & 0,92 & 0,92 & 0,92 & & & 5 & \\
\hline 17. Perceber que simplesmente não vale à pena beber. & 0,80 & 0,88 & 0,96 & 4 & 1 & & \\
\hline $\begin{array}{l}\text { 18. Esperar até que todos os locais onde vendem bebidas } \\
\text { estejam fechados. }\end{array}$ & 0,68 & 0,64 & 0,60 & & & 5 & \\
\hline $\begin{array}{l}\text { 19. Lembrar como eu deixei minha família e amigos "para baixo", } \\
\text { mal, triste, em situações difíceis no passado. }\end{array}$ & 0,96 & 0,96 & 0,96 & & 5 & & \\
\hline 20. Manter-me longe das pessoas que bebem. & 1,00 & 1,00 & 1,00 & & & & 5 \\
\hline 21. Fazer uma caminhada. & 0,92 & 0,88 & 0,92 & & & 5 & \\
\hline $\begin{array}{l}\text { 22. Olhar o lado bom de parar com o uso de álcool e tentar parar } \\
\text { de inventar desculpas para mim mesmo. }\end{array}$ & 0,96 & 1,00 & 1,00 & 5 & & & \\
\hline 23. Perceber que o uso do álcool está afetando minha saúde. & 1,00 & 0,96 & 0,92 & 2 & 3 & & \\
\hline $\begin{array}{l}\text { 24. Começar a fazer alguma atividade em casa para me distrair e } \\
\text { evitar o uso do álcool. }\end{array}$ & 0,84 & 0,92 & 0,92 & & & 5 & \\
\hline $\begin{array}{l}\text { 25. Considerar os efeitos que o uso do álcool terá na minha } \\
\text { família. }\end{array}$ & 0,80 & 0,96 & 0,92 & 1 & 4 & & \\
\hline 26. Lembrar da boa vida que eu poderia ter sem beber. & 1,00 & 1,00 & 0,96 & 4 & & 1 & \\
\hline $\begin{array}{l}\text { 27. Fazer contato com amigos antigos que bebiam e estão } \\
\text { recuperados agora. }\end{array}$ & 1,00 & 1,00 & 1,00 & & & & 5 \\
\hline 28. Decidir que eu vou parar de "brincar" comigo mesmo. & 0,88 & 0,88 & 0,84 & 4 & 1 & & \\
\hline 29. Comer uma boa refeição. & 0,84 & 0,88 & 0,92 & & & 5 & \\
\hline 30. Evitar lugares onde eu bebia. & 1,00 & 1,00 & 1,00 & & & 5 & \\
\hline 31. Pensar que posso decepcionar as pessoas que me ajudaram. & 0,96 & 0,92 & 0,92 & 5 & & & \\
\hline 32. Dizer que estou bem e desejo continuar assim. & 1,00 & 0,92 & 0,92 & 5 & & & \\
\hline 33. Ir dormir. & 0,80 & 0,80 & 0,86 & & & 5 & \\
\hline 34. Lembrar de como isso afetou a minha família. & 1,00 & 0,96 & 0,92 & & 5 & & \\
\hline 35. Forçar-me a ir ao trabalho. & 0,96 & 0,92 & 0,92 & & & 5 & \\
\hline 36. Tentar enfrentar a vida ao invés de evitá-la. & 0,96 & 0,92 & 0,92 & 4 & & 1 & \\
\hline Total & 0,91 & 0,92 & 0,91 & & & & \\
\hline
\end{tabular}

CVC: coeficiente de validade de conteúdo; E/D: evitação/distração; PN: pensamento negativo; PP: pensamento positivo; SS: suporte social. 
químicos foi de extrema importância para a obtenção de uma avaliação criteriosa e de qualidade 6 .

A adaptação transcultural é o primeiro passo do processo de validação de uma escala e os resultados encontrados até o momento são semelhantes ao do estudo realizado na Espanha 5. A validação de conteúdo complementou e proporcionou maior consistência a esse processo 6 . No entanto, seria considerável realizar uma avaliação das propriedades psicométricas do CBIversão brasileira e estudo de análise fatorial da escala, bem como a validade de constructo e a análise da consistência interna, sendo estas as limitações do estudo. Por outro lado, a proposta básica de tradução e adaptação da escala torna possível identificar quais as estratégias de coping são mais utilizadas e se os tratamentos propostos proporcionam um uso mais frequente ou não das mesmas. Além do mais, ao dar sequência aos estudos sistemáticos para a verificação de evidências de validade e de sensibilidade há também a possibilidade de uso clínico.

A versão brasileira do CBI apresentou concordância e índices satisfatórios para a aplicação por telefone no Brasil. No entanto, são necessários outros estudos; nós realizamos a primeira etapa na adaptação deste instrumento, que avalia as estratégias de coping específicas para alcoolistas.

\section{Resumen}

Las estrategias de afrontamiento contra el alcohol se relacionan directamente con el éxito de la abstinencia. En Brasil no existen instrumentos para identificar estrategias específicas para consumidores de alcohol. El objetivo del estudio ha sido realizar la traducción, adaptación transcultural y validación del contenido de Coping Behaviours Inventory (CBI). Los procedimientos fueron traducción y retrotraducción, adaptación cultural, evaluación del contenido y estudio piloto. La versión final portuguesa fue administrada por vía telefónica en 40 consumidores de alcohol que buscan ayuda en un servicio telefónico, VIVAVOZ. La versión retrotraducida se acercó a la original. La validación del contenido en la mayoría de los artículos es satisfactoria y aceptable. Además, el acuerdo entre los especialistas sobre la dimensión teórica, presentó un índice medio kappa de 0,666, siendo un nivel de acuerdo considerado substancial. Los resultados se muestran satisfactorios y aceptables, lo que demuestra que la escala es adecuada para investigar las estrategias de afrontamiento en los consumidores de alcohol.

\section{Colaboradores}

H. M. R. M. Constant participou na concepção e projeto, análise e interpretação dos dados, redação do artigo, revisão crítica relevante do conteúdo intelectual e aprovação final da versão a ser publicada. L. R. Figueiró, L. Signor, N. K. Bisch, H. M. T. Barros e M. Ferigolo colaboraram na análise e interpretação dos dados, redação do artigo, revisão crítica relevante do conteúdo intelectual e aprovação final da versão a ser publicada.

\section{Agradecimentos}

Os autores agradecem à Secretaria Nacional de Políticas Sobre Drogas (SENAD) e à Associação Mário Tannhauser de Ensino, Pesquisa e Assistência (AMTEPA) pelo apoio financeiro para o funcionamento e para as pesquisas desenvolvidas no VIVAVOZ, além das bolsas de mestrado e doutorado (H.M.R.M.C., L.R.F., L.S., N.K.B.). Reconhecem também o apoio do CNPq, por intermédio de bolsa de Produtividade de Pesquisa 1C (H.M.T.B.). 


\section{Referências}

1. Marlatt GA, Donavan DM. Prevenção da recaída: estratégias de manutenção no tratamento de comportamentos adictivos. 2a Ed. Porto Alegre: Editora Artmed; 2009.

2. Monti PM, Kadden RM, Rohsenow DJ, Cooney NL, Abrams DB. Tratando a dependência de álcool: um treinamento das habilidades de enfrentamento. 2 Ed. São Paulo: Roca; 2005.

3. Littmann GK, Stapleton J, Oppenheim AN, Peleg M. An instrument for measuring coping bahaviours in hospitalized alcoholics: implications for relapse prevention treatment. Br J Addict 1983; 78:269-76.

4. Savóia MG, Santana PR, Mejias NP. Adaptação do inventário de estratégias de coping de Folkman e Lazarus para o Português. Psicol USP 1996; 7: 183-201.

5. Gonzáles RG, Suárez MA. Evaluación en programas de prevención de recaída: adaptación española del Inventario de Habilidades de Afrontamiento (CBI) de Litman en dependientes del alcohol. Adicciones 2002; 14:455-63.
6. Pasquali L. Instrumentação psicológica: fundamentos e prática. Porto Alegre: Editora Artmed; 2010.

7. Hernández-Nieto RA. Contribuciones al análisis estadístico. Mérida: Universidad de los Andes/ IESINFO; 2002.

8. Barros HM, Santos V, Mazoni C, Dantas DC, Ferigolo M. Neuroscience education for health profession undergraduates in a call-center for drug abuse prevention. Drug Alcohol Depend 2008; 98:270-4.

9. Landis JR, Koch GG. The measurement of observer agreement for categorical data. Biometrics 1977; 33:159-74.

10. Giglioti A, Guimarães A. Diretrizes gerais para tratamento da dependência química. Rio de Janeiro: Editora Rubio; 2010.

Recebido em 10/Out/2013

Versão final reapresentada em 28/Mar/2014

Aprovado em 30/Jul/2014 